\title{
OS LIMITES SISTÊMICOS DA COMUNICAÇÃO DA JURISDIÇÃO TRADICIONAL PARA TRATAR DE CONFLITOS AFETIVOS
}

Júlia Francieli Neves de Oliveira ${ }^{1}$

Leonel Severo Rocha ${ }^{2}$

\section{RESUMO}

$\mathrm{Na}$ modernidade em que as relações familiares são extremamente complexas e ressignificadas, o direito precisa promover novas formas de organização, diálogos e capacidades para observar os conflitos. Analisa-se o tratamento dos conflitos familiares à luz da teoria dos sistemas, com enfoque na teoria sociologica de Luhmann que propõe uma abordagem histórica a partir de textos e narrativas através dos quais procura analisar o surgimento do código e da nova semântica do amor e Bourdieu dedica ao amor como ruptura com a estrutura dissimétrica da violência simbólica em que se constitui a dominação masculina.

Palavras-chave: Dominação, Direito de família, Gênero, Sociologia, Teoria dos Sistemas.

\section{THE SYSTEMIC LIMITS OF THE COMMUNICATION OF TRADITIONAL JURISDICTION TO TREAT AFFECTIVE CONFLICTS}

\section{SUMMARY}

In modernity where family relationships are extremely complex and re-signified, law must promote new forms of organization, dialogue, and ability to observe conflicts. We analyze the treatment of family conflicts in the light of systems theory, focusing on the sociological

\footnotetext{
${ }^{1}$ Doutoranda em Direito Público pelo Programa de Pós-graduação em Direito da Universidade do Vale do Rio dos Sinos - UNISINOS/RS. Mestre em Direito da Universidade Regional Integrada do Alto Uruguai e das Missões - URI/RS, Campus Santo Ângelo. Pós-Graduada Lato Sensu em Direito Processual Civil, pela Universidade Anhanguera - UNIDERP. Pesquisa parcial realizada no grupo Teoria do Direito, da UNISINOS, analisa-se as contribuições realizadas pelos principais expoentes da teoria dos sistemas autopoiéticos para a renovação do Direito. Bolsista em Pesquisa do CNPq. Advogada. Endereço Postal: Barão de Santo Ângelo, 1385, Cep. 98804432, Santo Ângelo/RS. E-mail: julianeves15@hotmail.com.

${ }^{2}$ Doutorado pela Ecole des Hautes Etudes en Sciences Sociales de Paris. Pós-doutorado em Sociologia do Direito pela Universita degli Studi di Lecce. Atualmente é Professor Titular da Universidade do Vale do Rio dos Sinos e Coordenador Executivo do Programa de Pós-Graduação em Direito. Pós-Doutor em Sociologia do Direito (Universitá degli Studi di Lecce/Itália), Doutor em Direito (Ecole des Hautes Etudes em Sciences Sociales Paris/França). Coordenador Executivo do Programa de Pós-Graduação em Direito (Mestrado e Doutorado) da UNISINOS - Universidade do Vale do Rio dos Sinos. Pesquisador II do CNPq. Associado Honorário e ExPresidente do CONPEDI (Conselho Nacional de Pesquisa e Pós-Graduação em Direito). Endereço Postal: Rua Independência, 1055, apto 1805, centro, Cep. 93010-004. São Leopoldo/RS. E-mail: leonel.rocha@uol.com.br
} 
theory of Luhmann that proposes a historical approach from texts and narratives through which seeks to analyze the emergence of the code and the new semantics of love and Bourdieu dedicates to love as a rupture with the dissymmetric structure of symbolic violence in which male domination is constituted.

Keywords: Domination, Family Law, Gender, Sociology, Systems Theory.

\section{INTRODUÇÃO}

O objetivo central desse estudo consiste em desenvolver uma reflexão sob as relações da intimidade e suas características identitárias construídas pelas culturas ocidentais. Percebese desde logo, um viés que privilegia as relações de dominação do homem sobre a mulher como definidoras da observação sociológica mais relevante. A lógica de resistência à dominação masculina assumido historicamente pelas mulheres sob a ótica de P. Bourdieu e sob a perspectiva do amor nos relacionamentos que podem influenciar socialmente para a superação, do até então, paradigma da naturalização das identidades de feminino e masculino de na teoria N. Luhmann. Portando os sociólogos mais importantes que estudam a questão da intimidade na França Luhmann e na Alemanha Bourdieu, serão os principais autores estudados no presente artigo.

A metodologia a ser utilizada é a matriz teórica sistêmica que se dá pela abordagem sociológica, tanto conceitual quanto empírica dos sistemas jurídico. A observação da sociedade enquanto sistema apresenta vantagens porque permite a análise da sua complexidade por meio da reconstrução do saber jurídico e da práxis judicial, de um ponto de vista interdisciplinar, para o enfrentamento das incertezas da sociedade contemporânea em uma perspectiva evolutiva e construtiva.

A ideia de buscar a relação entre sociedade, direito e justiça, num contexto democrático, para que se reduza a distância entre teoria e prática, pressupõe assim estudos sociológicos sobre a lógica organizacional e o funcionamento das instituições. A teoria dos sistemas é sociologia jurídica em condições de oferecer subsídios a uma verificação empírica que permitirá a crítica e as sugestões para a melhor adaptação do sistema jurídico aos meios de tratamento de conflitos. 
Para enfrentar o tema em questão, o presente trabalho apresenta-se dividido em três enfoques. Inicialmente, se investiga o que se entende por Amor e a dominação na visão de P. Bourdieu a relação de dominação masculina que historicamente vem se perpetuando. $\mathrm{Na}$ segunda parte deste trabalho se analisa a perspectiva do amor simbolicamente generalizado em Luhmann. A terceira parte se procura verificar a relação entre o amor como meio de comunicação e direitos fundamentais positivados. Por último realiza-se uma analise dos limites sistêmicos da comunicação da jurisdição tradicional para tratar de conflitos afetivos.

\section{DESENVOLVIMENTO/ REFERENCIAL TEÓRICO}

\section{A dominação de P. Bourdieu}

Bourdieu esclarece que a dominação masculina pode ser compreendida como tendo sustentação em uma divisão arbitrária entre homens e mulheres. Esta divisão é concebida através de oposições binárias, que classificam uns e outros segundo adjetivos opostos, sendo reservados os positivos a homens e os negativos a mulheres (BOURDIEU, 2002, p. 19). E esta maneira de se classificar é o princípio de um trabalho de construção social dos corpos, que visa tornar verdadeira a divisão arbitrária que o próprio esquema de pensamento dominante formula.

Esses esquemas de pensamento, de aplicação universal, registram como que diferenças de natureza, inscritas na objetividade, das variações e dos traços distintivos (por exemplo em matéria corporal) que eles contribuem para fazer existir, ao mesmo tempo que as naturalizam, inscrevendo-as em um sistema de diferenças, todas igualmente naturais em aparência; de modo que as previsões que eles engendram são incessantemente confirmadas pelo curso do mundo, sobretudo por todos os ciclos biológicos e cósmicos (BOURDIEU, 2002, p. 16).

Ao ampliar sua reflexão, ele menciona que há duas operações imprescindíveis nesta sociodicéia masculina: “ela legitima uma relação de dominação inscrevendo-a em uma natureza biológica que é, por sua vez, ela uma própria construção social naturalizada” (BOURDIEU, 2002, p. 33). Ou seja, de acordo com Bourdieu “[...] incorporamos, sob a forma de esquemas inconscientes de percepção e de apreciação, as estruturas históricas de ordem masculina; arriscamo-nos, pois, a recorrer, para pensar a dominação masculina, a modos de pensamento que são eles próprios produto da dominação” (BOURDIEU, 2002, p. 
13). Constata-se, assim, que através de violência física e de fatores subjetivos foi ensinado o que cabe aos homens e às mulheres, denominado pelo autor como habitus (BOURDIEU, 2002, p. 41). Para o autor, a construção social de homens e mulheres - que se incorpora, de fato, fazendo parecer que é natural esta maneira de concebê-los - está fundada na ordem simbólica (BOURDIEU, 2002, p. 45), acreditando que o caminho de reversão do processo de dominação aponta para aquilo que ele chama de revolução simbólica. Esta revolução consistiria em modificar as “condições sociais de produção” dos discursos (BOURDIEU, 2002, p. 100-115), aos quais são expostos duradouramente dominantes e dominados, fazendo uso das instituições produtoras e reprodutoras do discurso de dominação (família, escola, Estado e Igreja).

Ao abordar a problemática da dominação masculina, Bourdieu (1998) interroga-se, sobre a possibilidade de, no quadro da relação homem/mulher, o amor funcionar como elemento de neutralização dessa dominação: será que o amor "suspende a relação de dominação masculina e a sua violência simbólica ou não deixa de a perpetuar com subtileza?” (Bourdieu, 1998: 116).

A resposta de Bourdieu parece clara. É possível que o amor tenha esse poder de suspender a dominação masculina, mas há condições para que ela possa de facto ocorrer. Por um lado, não se trata de uma aquisição de uma vez por todas: “só através de um trabalho de todo os instantes, recomeçado sem cessar, se pode arrancar às águas frias do cálculo, da violência e do interesse, essa "ilha encantada" do amor, esse mundo fechado e perfeitamente autárcico que é o lugar de uma série continuada de milagres. São eles o da não-violência, que torna possível a instauração de relações fundadas na plena reciprocidade e autorizando o abandono e a entrega de si; o do reconhecimento mútuo, que permite, como diz Sartre, o sentir-se 'justificado por existir` (...); o do desinteresse que torna possíveis as relações desinstrumentalizadas (...)” (Bourdieu, 1998: 117).

A igualdade entre pares, no contexto da relação amorosa, constitui assim peça fundamental para que o milagre que suspende a 189 dominação se concretize: “o sujeito amoroso só pode obter o reconhecimento de um outro sujeito, mas que abdique, como ele próprio, da intenção de dominar;” (Bourdieu 1998: 119). 
E Bourdieu continua, num texto que trai o sujeito que fala do que sabe porque ama ou amou, falando da relação amorosa com um outro igual na procura de comunhão e fusão, testemunhada na utilização sem cessar de redundâncias, como os repetidos "amo-te, amasme?” e na atribuição de inúmeros nomes carinhosos e dos termos com que se “nomeia” o outro. Termina, em sentido convergente com os autores que temos vindo a referir, mostrando como o amor pode surgir como um lugar de transcendência e de resistência às instituições. "Reconhecimento mútuo, troca de justificações de existir e de razões de ser, testemunhos mútuos de confiança, tantos sinais da reciprocidade perfeita que confere ao círculo no qual se encerra a díade amorosa, unidade social elementar, inseparável e dotada de uma poderosa autarcia simbólica, o poder de rivalizar vitoriosamente com todas as consagrações que se pedem habitualmente às instituições e aos rituais da "Sociedade”, esse substituto mundano de Deus”.

Relações afetivas, o amor e o casamento: um olhar específico Procurando fazer uma pequena síntese, pode concluir-se que, apesar da diversidade das perspectivas analisadas, há dois temas que as atravessam e aproximam. Trata-se, por um lado, do tema da relação entre modernidade e amor romântico e, por outro, da questão dos efeitos da chamada questão feminina na vivência do sentimento amoroso. Embora elas sejam temáticas associadas entre si, vale a pena, num primeiro momento, distingui-las.

Bourdieu se questiona da possibilidade de o "amor puro" ser possibilidade de ruptura com a dominação masculina: "Seria o amor à exceção, a única, mas de primeira grandeza, à lei da dominação masculina, uma suspensão da violência simbólica, ou a forma suprema, porque a mais sutil e a mais invisível, desta violência?” (2005, p. 129). Apontar no amor a forma de doação de si e do corpo, levando em conta o outro em suas finalidades, em ruptura com a circulação mercantil como objeto e no trato do outro como instrumento, é contribuição inestimável e inesgotável de Bourdieu à compreensão das formas de resistência à dominação masculina. A “aura de mistério” desse “amor puro” é compreensível de uma perspectiva antropológica:

baseado na suspensão da luta por um poder simbólico que a busca de reconhecimento e a tentação correlativa de dominar suscitam, o reconhecimento mútuo pelo qual cada um se reconhece no outro e o 
reconhece também como tal pode levar, em sua perfeita reflexividade, para além da alternativa do egoísmo e do altruísmo ou até da distinção do sujeito e do objeto, a um estado de fusão e de comunhão, muitas vezes evocado em metáforas próximas às do místico, em que dois seres podem 'perder-se um no outro' sem se perder (BOURDIEU, 2005, p. 132).

São belas as páginas que Bourdieu dedica ao amor como ruptura com a estrutura dissimétrica da violência simbólica em que se constitui a dominação masculina. $\mathrm{O}$ amor convoca o sujeito a uma nova postura frente ao outro, a ser sujeito amoroso, que "só pode obter o reconhecimento de um outro sujeito, mas que abdique, como ele o fez, da intenção de dominar” (BOURDIEU, 2005, p. 132).

Reconhecimento mútuo, troca de justificações de existência e de razões de ser, testemunhos recíprocos de confiança, signos, todos, a total reciprocidade que confere ao círculo em que se encerra a díade amorosa, unidade social elementar, indivisível e dotada de uma potência autárquica simbólica, o poder de rivalizar vitoriosamente com todas as consagrações que ordinariamente se pedem às instituições e aos ritos da "Sociedade", este substituto mundano de Deus (BOURDIEU, 2005, p. 132-133).

Sem adjetivos, o amor é o não poder por excelência e convoca ambos os sujeitos amorosos, de modo relacional, a uma nova forma de existência um para o outro.

\section{A narrativa de Luhmann - O Amor como Paixão}

Em meados dos anos 80, Luhmann preocupa-se com a perspectiva das relações entre o sistema social e o que designa como meios de comunicação simbolicamente generalizada trata a temática do amor-paixão como um estudo de caso exatamente sobre a emergência desses códigos de comunicação simbólica generalizada. Para Luhmann, o amor não é um sentimento, 
pois nos interessamos, pela qualidade psíquica da dimensão dos sentimentos. Propõe uma abordagem histórica a partir de textos e narrativas através dos quais procura analisar o surgimento do código e da nova semântica do amor.

É interessante que em Luhmann não há relacionamentos amorosos unilaterais, nem paixões infelizes, nem de saudades não preenchidas. Os relacionamentos amorosos são sempre expectativas afinadas mutuamente, ou seja, há apenas relações amorosas estáveis, casamentos e parcerias, porque só elas formam um sistema sociologicamente interessante chamado “intimidade” (Luhmann, 1991, p.52).

Depois de mostrar as especificidades da afirmação da "semântica" do amor romântico na França, na Alemanha e na Inglaterra, associando a sua afirmação a outros aspectos do desenvolvimento dos sistemas sociais e também do contexto filosófico mais global de cada país, Luhmann revela as contradições em que essa “ideologia” parece, desde logo, estar encerrada (Luhmann, 1986, p. 136).

Alimenta-se da noção de fruição do eu e da multiplicidade das experiências, mas, ao mesmo tempo, sublinha a distância e a esperança mais do que a satisfação imediata do desejo. Mostra como este “complexo semântico” acentua as diferenças entre homens e mulheres - “o homem amava amar, a mulher amava o homem” (Luhmann, 1986, p. 136).

Esta perspectiva da assimetria dos sexos e do papel dos homens no amor romântico está bem ilustrada em várias obras de que o de L’Amour de Stendhal (1962), escrita no primeiro quarto do século XIX, é apenas um brilhante exemplo. Trata-se quase de um manual de bem amar, obra de um homem sensível destinada a outras almas sensíveis, em que se ensina a distinguir entre a simples galanteria ou o amor-gosto das verdadeiras e desinteressadas paixões, que se dão bem melhor com a espontaneidade dos sentimentos do que com retórica.

A explicação da assimetria entre homens e mulheres, reservando aos primeiros um papel ativo e às segundas um papel expectante, relaciona-se ainda com as atribuições familiares da mulher, necessitando esta de se defender de propósitos menos honestos. Enquanto as mulheres deveriam preservar a sua intimidade, só se entregando por amor uma 
vez e para todo o sempre, para os homens o exercício das artes do amor só poderia trazer experiência, sabedoria, aperfeiçoamento, sensibilidade.

Traça-nos, em suma, um retrato riquíssimo e muito informado, até chegar à análise da relação entre o casamento e o amor romântico nos nossos dias, explicando as mudanças socioestruturais e a diferenciação dos sistemas propiciadores de que os laços familiares e de parentesco deixassem de ocupar lugar central na regulação das funções económicas, políticas e religiosas, tornando assim possível uma relação mais próxima entre inclinação amorosa e casamento.

Por sua vez, as narrativas românticas vinham ganhando terreno e difundindo-se criando novas éticas de comportamento. Elas generalizaram-se gradualmente a toda a Europa desde o século XVII. Daí que, para Luhmann, este estudo de caso constitua também excelente ilustração do que ele considera ser o surgimento dos meios de comunicação simbólica generalizada.

Na verdade, o modelo do amor romântico acaba por se generalizar e impor, com adaptações, às sociedades ocidentais desde essa época até aos nossos dias. Assim, se as estruturas sociais estavam preparadas para que as relações familiares pudessem assumir novas configurações também estava já disponível a semântica do amor romântico, capaz de funcionar como modelo e código dos novos comportamentos. Assumindo tendências diferenciadas de acordo com os países, em França orientada para as paixões fora do casamento, na Inglaterra mais voltada para a domesticidade e na Alemanha, em parte, para a educação, a nova semântica do amor dava resposta aos anseios de liberdade de escolha no casamento: "Pelo fim do século XVIII a unidade entre o casamento por amor e o amor conjugal era geralmente professada como o princípio da natureza perfeita da humanidade” (Luhmann, 1986, p. 146).

Mas com a sua associação ao casamento, o amor romântico, o amor paixão, foi assumindo versões mais suavizadas, chegando mesmo a começar a esboçar-se a separação entre paixão -- vertigem, desordem -- e amor e até a criticar-se o casamento só por paixão (Luhmann, 1986, p. 148). Começam também a mostrar-se os problemas da trivialização do sentimento amoroso ao longo do casamento, verificando-se a distância entre o amor, só para 
alguns, visto e popularizado nos livros e nos filmes e o quotidiano conjugal. Retrabalha-se, assim, o código, suavizam-se os seus aspectos mais “apaixonados” da primeira metade do século XVII.

O desenvolvimento de uma nova semântica da intimidade relaciona-se também com os movimentos de diferenciação dos sistemas sociais. Na verdade, o desenvolvimento económico e as relações de mercado, a opacidade das relações sociais, afirma Luhmann, impõem a distinção cada vez mais clara entre "as relações impessoais e as pessoais" (Luhmann, 1986, p.152).

A generalização das relações impessoais e dos critérios de comportamento universalistas em contextos em que os indivíduos não são reconhecidos enquanto tal e, em que, nas suas múltiplas funções, não assumem a unicidade das suas experiências e da sua identidade, tem como consequência a necessidade de intensificação das relações pessoais: "Uma vez que esta experiência básica da diferença entre relações impessoais e pessoais se tornou conhecimento comum, uma vez que se tornou verdadeira para toda a gente, independentemente do sexo e do estrato social, ela tem de cristalizar o desejo de relações pessoais, de uma maior interpenetração, a um nível mais profundo e fazê- lo aparecer como ainda mais inatingível” (Luhmann, 1986, p.153).

A identificação desta nova semântica da intimidade, segundo Luhmann, acaba por nos conduzir aos paradoxos e dificuldades dos nossos dias, no final do século XX. De um lado, e devido às transformações socioestruturais, os indivíduos têm mais autonomia em relação às instituições, o que se traduz em acrescida margem de manobra individual. A crescente paridade entre homens e mulheres é exemplo dessas transformações e dessa maior autonomia.

Mas, por outro lado, a necessidade da intensificação das relações pessoais aumenta as expectativas em relação ao desejo de ser compreendido pelo outro e torna-se difícil, senão impossível, que o seu retrato idealizado se sustente no quotidiano (Luhmann, 1986, p. 165). Expectativas mais elevadas implicam também, ao não serem ajustadas à realidade, maiores desilusões, crescente instabilidade e incerteza. E o autor termina afirmando que o amor, nas sociedades contemporâneas, promete muito, mas acaba por dar pouco. 
O código do amor transformou-se de um ideal, através dos paradoxos referidos, num problema. No passado tinham sido levantadas algumas objecções a este acento tónico de Luhamnn no lado da improbabilidade do amor. Na investigação sobre o casamento voltou a ser abordado este tema já que se operacionalizou especificamente a questão do sentimento amoroso. Os entrevistados, nessa pesquisa, fazem também nítida separação entre paixão e amor conjugal. Embora as experiências sejam diversas, alguns dos mais jovens relatam que, tendo sido a paixão o motor inicial da aproximação conjugal, ela se veio a transformar, mais tarde, num sentimento tranquilo, que se foi construindo e cimentando ao longo da relação.

Não nos aparece generalizadamente a imagem dilacerada grandes promessas, fracas realidades, que pode estar implícita nas análises de Luhmann, embora se tenha encontrado, igualmente, uma ou outra situação conflitual, quando se nota o desajuste entre expectativas perante o comportamento do outro e realidades vividas no quotidiano.

Analisar-se-á o sistema jurídico sobre o risco no Direito de Família. Luhmann começa por distinguir os conceitos de risco versus perigo e de risco versus segurança. A noção de risco depende mais do modo como é observado e não tanto das suas pressupostas características objetivas (1993, p.27).

O risco tornou-se uma variante que distingue entre aquilo que é desejado e indesejado. Para o autor, o risco e o perigo estão ambos associados à ideia de potencial perda futura; no entanto, a sua posição defende a distinção de ambos os conceitos. Segundo Luhmann, podemos falar em perigo se as consequências ou prejuízos decorrentes de um determinado acontecimento de forma independente da nossa vontade, ou seja, se a origem do evento provier de fontes externas. Pelo contrário, podemos falar em risco quando determinados acontecimentos tiverem origem em decisões próprias (1993, p.30).

O autor recorre aos seguintes exemplos: Quem fuma aceita o risco de morrer de cancro, embora para quem inala o fumo dos outros o cancro deve ser visto como um perigo. Alguém que assume o risco de morrer num acidente automobilístico, por decidir conduzir a alta velocidade, transforma esta situação num perigo para os outros motoristas. Assim, a mesma ação pode ser um risco para uns e um perigo para outros. Apesar da distinção que Luhmann faz dos dois conceitos (risco e perigo), ele também acrescenta que ambos se encontram intimamente interligados (1993, p.30). 
Engendram-se assim uma sociedade intimista, isto é, o indivíduo deve desvendar a todo o momento a sua personalidade, as suas motivações e emoções e exprimir seus sentimentos mais íntimos. Para Luhman, a sociedade atual caracteriza-se por um maior número de possibilidades de estabelecer relações interpessoais e maior intensificação dessas relações. Por outro lado, na modernidade há dificuldade de se prever a evolução da própria sociedade aos indivíduos como opaca e complexa.

Esses fatores levariam o sujeito a ter a necessidade de se refugiar num mundo próximo e compreensível, transmitindo uma sensação de confiança, um mundo íntimo.

Desta forma Luhmann faz uma análise funcional do amor como paixão: “está na pesquisa comparada que relaciona entre si várias causas possíveis de um mesmo efeito ou vários efeitos possíveis de uma mesma causa”, com o que desvendou novas possibilidades na relação entre fenômenos sociais, tratando causas e efeitos como simples variáveis intermutáveis, e não como estruturas ontológicas (1991, p.VIII).

Convém falar de sistemas no plural, pois, para Luhmann, o jogo das interações sociais produz um conjunto de sistemas e subsistemas mais ou menos articulados e estruturados ao nível interno, que geram um patrimônio de expectativa de conduta, de juízos de valor e de soluções alternativas tendentes a reduzir a complexidade do mundo (entendido como horizonte de experiências) (1991, p. VIII).

Da mesma maneira, nenhum grupo pode determinar esse processo na base dos seus interesses específicos. A sua abordagem, se assim efetuada, desvaloriza a dinâmica de conflito e de tensão entre grupos de agentes, acentuando a diferenciação funcional, entendida como processo incessante de produção de novas estruturas capazes de definir as ações admitidas excluídas (1991, p. IX).

As investigações aqui apresentadas sobre a semântica do amor combinam dois contextos teóricos diferentes. "Por um lado, situam-se no âmbito de trabalhos da sociologia do conhecimento que se ocupam da transição de formas de sociedade tradicional para a moderna” (Luhmann, 1991, p. 07).

Estamos no segundo contexto com as bases de uma teoria global dos meios de comunicação simbolicamente generalizados. Assim sendo, o amor não será aqui tratado como um sentimento nem mesmo apenas como um seu reflexo, mas antes como um código simbólico que informa sobre o modo como se pode comunicar com êxito, mesmo nos casos 
em que tal poderia parecer impossível. O código encoraja a formação de sentimentos correspondentes. Sem ele, a maioria, segundo La Rochefoucauld, jamais poderia ter acesso a tais sentimentos. E as inglesas que procuram se orientar por romances pré-vitorianos, têm até de esperar por sinais visíveis de amor disposto para o matrimônio, antes de poderem descobrir conscientemente o que é o amor. Não se trata, assim da pura invenção de uma teoria sociológica, mas de um quadro de circunstâncias há muito refletido na semântica do amor, por exemplo, com o poder, com o dinheiro, com a verdade; com isso, ela ganha em conhecimentos, revelando que o amor não é apenas uma anomalia, mas antes uma improbabilidade absolutamente normal (Luhmann, 1991, p. 08).

A investigação histórica mostra complementarmente, com base nesta teoria, que as diferenças entre o complexo amour passion dos franceses e o casamento/ companionship típico dos puritanos afirmaram, especialmente a este respeito, contêm de contatos distintos: apenas a semântica do amor como paixão foi, pormenorizadamente, suficientemente complexa para poder absorver a valorização da sexualidade no século XVIII; por isso, embora tenha contribuído mais para a valorização do amor e do casamento, só conseguirá criar, nas mesmas condições, o monstro da moral sexual vitoriana. Nesta sequência histórica surge, precisamente na diferença de reação perante o mesmo problema, um contexto de circunstâncias, reconheço que, metodologicamente insuficientemente esclarecido (Luhmann, 1991, p. 09).

\section{O amor como meio de comunicação e a sua relação com o Direito}

O Direito atravessa uma outra fase teórica, o avanço para a discussão a respeito da racionalidade do Direito e da sociedade, que segundo Luhmann, pode ser chamado de autopoiética, devido às concepções de risco e de paradoxo. É caracterizada pela complexidade da dupla contingência, ou seja, problemas que ocorrem quando deve-se esperar a conduta de outra pessoa. Na sociedade complexa, a categoria do risco, torna-se um elemento decisivo: é um evento generalizado da comunicação, sendo uma reflexão sobre as possibilidades de decisão (LUHMANN, 1983, p. 12). 
O risco vem acompanhado da reflexão sobre a "segurança”. Nesta ótica, Luhmann prefere colocar o risco em oposição ao “perigo”, por entender que os acontecimentos sociais são provocados por decisões contingentes (poderiam ser de outra forma), que não permitem mais se falar de decisão segura. A sociedade moderna possui condições de controlar as indeterminações, ao mesmo tempo que não cessa de produzi-las. Isso gera um paradoxo na comunicação. Por isso, a pesquisa jurídica deve ser dirigida para uma nova concepção da sociedade, centrada no postulado de que o risco é umas das categorias fundamentais para a sua observação (LUHMANN, 1993, p.58).

Na teoria sistêmica e na sociedade do terceiro milênio, vivencia-se então o chamado sistema social hipercomplexo, ou seja, a possibilidade de recorrer-se a diferentes sistemas, para o enfrentamento de questões específicas. As decisões não dependem somente dos indivíduos, mas das organizações, pois estas têm a função de tomar decisões a partir de cada sistema (ROCHA, 2013, p.43).

$\mathrm{Na}$ atual forma da sociedade, com a presença permanente do risco, percebe-se o inevitável paradoxo, impõe-se colocando a importância de uma nova racionalidade para a tomada das decisões nas sociedades complexas, redefinindo a filosofia analítica, a hermenêutica e a pragmático-sistêmica, que desbloqueiam a comunicação jurídica. Nessa ordem de raciocínio, a pesquisa jurídica deve ser dirigida para uma nova forma de sociedade, centrada no postulado de que a complexidade é uma das categorias fundamentais para a sua observação. Nota-se a necessidade de uma transformação da política e do Direito (ROCHA, 2013, p.44).

No momento em que o Estado, enquanto programador do Direito, deixa de ser o centro de organização da política e deixa de ser o fundamento único de validade da lei, o Judiciário, em vez de simplesmente aplicar a programação condicional que caracteriza um sistema fechado, necessita recorrer às fundamentações extraestatais e toma-o decisões de outro tipo, que é através da programação finalística que caracteriza um sistema aberto (ROCHA, 2013, p.44).

Assim, a tendência do Direito, em todas as áreas e principalmente no Direito de Família, que envolve o sentimento, é a de transformar o Judiciário em um sistema aberto, 
observando as suas consequências cognitivas, pois é preciso pensar na riqueza da alteridade. A complexidade da produção de sentido do Direito como paradoxo torna-se, assim, uma condição para a observação da comunicação do Direito, uma vez que esta constitui a capacidade da linguagem e da evolução social.

Entra-se na cultura pós-moderna, ou seja, no interior de uma sociedade que conseguiu neutralizar a apatia, o que fundamentava o impulso modernista, isto é, a mudança. Com a dissolução da crença e da verdade divina e suprema implantada pela sociedade, surgiu a institucionalização da dúvida. O processo de construção de identidade pessoal, que possui uma multiplicidade de papéis e valores que se oferecem ao indivíduo, já não se faz acompanhar por referentes orientadores.

O reconhecimento formal, por parte da legislação, da jurisprudência ou da doutrina, tem desempenhado importante papel na busca pela igualdade de direitos sociais e civis dos gêneros. A nossa sociedade laica está estabelecendo uma cultura solidária e baseada nos direitos universais do homem e da mulher.

A partir do pressuposto de que nem sempre foi assim - no tocante a relação de dominação - e de que não há poder - pautado em identidade e diferença - inocente, conclui-se que é apontada a necessidade da desconstrução cultural da naturalização das identidades de feminino e masculino e a superação da relação de dominação, consolidada na opressão e inferiorização das mulheres, que não impediu o reconhecimento da identidade de mulher, mas que o tornou distorcido sob um olhar tendencioso e masculino.

O aparato conceitual construído por Pierre Bourdieu é fecundo para a análise das condições da dominação masculina como violência simbólica. As suas conseqüências para a reflexão sobre as possibilidades de resistência e de um Direito transformador são evidentes e inerentes à própria elaboração do sociólogo. Enquanto violência simbólica, a dominação masculina se constrói na história tomando como essências construções, formas de classificação a partir de princípios de visão e divisão cujo objetivo é a construção de uma ordem de dominação e que, sexual, tem no masculino o seu paradigma.

Pelo habitus se constata a construção de hexis corporal sob a matriz da cosmovisão androcêntrica, de modo relacional em que homem e mulher, e também gays e lésbicas, de forma consciente e inconsciente, têm seus corpos construídos ao modo da ordem de dominação. Essa forte construção teórica é já uma resistência à ordem de dominação. Da 
natureza relacional da dominação simbólica se conclui que toda ação transformadora deve transformar também aquele que a empreende, quer dizer, deve incluí-lo em seu questionamento.

Toda crítica de fundo implica autocrítica, numa ruptura com a posição de vítima. Mais que isso, que deve levar em consideração todos os espaços sociais, além da família, a escola, a igreja, o esporte, o jornalismo. Pode-se, num exercício de utopia crítica, vislumbrar que a sociedade que emergirá lentamente dessa luta não será a reprodução de nenhum modelo, nem das sociedades primitivas e igualitárias, nem de sociedades onde as mulheres, homens, negros, gays, lésbicas, teriam mais poder uns que os outros. O processo de igualdade de gêneros é um processo contínuo e atualmente dependente de uma mudança cultural buscando consolidar o processo de igualdade de gêneros, que encaminhem para a verdadeira tolerância, que pressupõe o respeito mútuo por meio de um processo de conscientização.

\section{Os limites sistêmicos da comunicação da jurisdição tradicional para tratar de conflitos afetivos}

A sociedade vem passando por inúmeras mudanças e transformações culturais e sociais. Junto aos benefícios trazidos pela modernidade ocorre também um aumento significativo de conflitos entre as pessoas.

O poder judiciário encontra-se esgotado devido a grande demanda de litígios que são postos a sua apreciação. As pessoas não conseguem mais resolverem seus próprios problemas e buscam na justiça uma resposta ao conflito, que foi gerado muitas vezes pela falta de comunicação e compreensão.

Nas relações familiares resolvidas perante o Poder Judiciário todos os aspectos emocionais e sentimentais envolvidos no conflito não são considerados pelo julgador, que apenas analisará fatos descritos. Muitas vezes a decisão se torna inútil e sem solução alguma, pois o conflito permanece e a decisão não gera efeito algum.

François Ost propõe, a partir de estudos de Direito e Literatura, uma renovação dos esquemas interpretativos do direito por meio de uma viagem às fontes do seu imaginário. É nesta jornada que o presente projeto toma assento para, na carona de Platão, afirmar a ordem jurídica inteira como "a mais excelente das tragédias". Se por um lado o Direito codifica a realidade, por outro a literatura libera os possíveis. Se o direito é o terreno da segurança, da 
certeza que é produzida pela pretensa completude da norma (sendo, apenas nos casos de omissão, dado ao juiz decidir o caso de acordo com a analogia, os costumes e os princípios gerais de direito, artigo $4^{\circ}$ da LINDB), a literatura é o terreno da surpresa, do inesperado (OST, 2004).

Se o direito produz pessoa, a literatura produz personagem - e se desdobra no particular e no concreto, afastada do terreno da abstração normativa que caracteriza as prescrições jurídicas. Mas devemos fazer justiça à literatura, sugere Ost. De fato, se nela nada é impossível, resta ver se essa imersão no particular não é justamente o caminho mais curto para se chegar ao universal - proposta de toda norma jurídica (OST, 2004).

A obra refere-se, assim, a uma compreensão dialética das relações direito-literatura, na medida em que "entre o 'tudo é possível' da ficção literária e o 'não deves' do imperativo jurídico, há, pelo menos, tanto interação quanto confronto. Nesta obra Ost pergunta "O que ganha o estudo do direito nesse confronto com o espaço literário?"( p.25). Certamente, a resposta não está no uso reduzido que se dá frequentemente à literatura, como reconhece Ost, nas sempre comuns citações literárias que pretendem dar uma ornamentação erudita ao discurso jurídico. Ou na utilização rasa de exemplos literários na tentativa de explicar teorias ou comprovar posições civilistica. Suas funções são muito mais abrangentes (OST, 2004).

Usa o autor também da metáfora do Dworkin, que compara o trabalho dos juízes à escrita de um romance em série. Esta é, pois, a tese do livro: uma teoria do direito contado, que privilegia o espírito do direito, preocupa-se antes com a "coerência narrativa" do raciocínio e evidencia a importância da interpretação do texto e da natureza argumentativa das discussões jurídicas. Nesse sentido, a vocação do jurídico seria a de oferecer "modelos narrativos" ao juiz, que, ao confrontá-los com o relato construído a partir dos fatos da causa, decidiria, estando menos preocupado com estruturas do que com a própria história (OST, 2004).

Trata-se uma observação transdisciplinar do Direito e da Sociedade. Chegando a proposta da autopoiese, que não tem uma resposta certa, mas sim uma maneira de se tentar observar uma forma diferente do Direito, e nessa observação, observar também a sociedade e outras áreas do conhecimento.

\section{Considerações Finais}


Associada aos ideais de liberdade dos sujeitos, em todos os seus sentidos, esta a necessidade de buscarmos um conceito de família que esteja acima de conceitos morais. Assim, devemos buscar um conceito de família que possa ser entendido em qualquer tempo ou espaço, já que família foi, e sempre será a célula básica da sociedade.

Deve-se, então, a partir da compreensão, e da constatação, de que é possível estabelecer um conceito universal para família, pode-se inferir, este estudo, que as relações de gênero foram firmadas ao longo dos tempos, sobre construções culturais de identidades masculinas e femininas, envolvendo relações de poder, o que resultou na naturalização dessas relações de dominação, fazendo com que o reconhecimento das mulheres na sociedade seja um reconhecimento distorcido.

No âmbito legal, a valorização do amor na pós-modernidade, que a seu turno vem marcada por um processo de mudanças sem precedentes na história do pensamento e da técnica, que levaram a uma alteração paradigmática no modo de se pensar a sociedade e suas instituições, passou a obedecer a valores novos que emergiram de uma sociedade que ansiou por uma liberdade ampla e irrestrita nas questões relacionais, tangenciando os direitos personalíssimos do cidadão (no que toca à sua liberdade e intimidade, bem como da proteção de seus direitos humanos fundamentais).

Observa-se, que na esfera do direito, os valores que permeiam o ordenamento integram a tradição da linguagem e da cultura. A sociedade encontra no direito, um lugar para que a tradição se mantenha, e o jurista, ao interpretar a lei, procure evidenciar a tradição, ou seja, os valores. Contudo a tradição não significa a manutenção presente de um passado, mas a atualização da experiência humana, que se desenvolve através da linguagem, onde o intérprete desempenha um importante papel de renovador, adaptando as exigências do momento presente às fórmulas herdadas pela tradição, utilizando-se dos valores jurídicos sociais.

Neste sentido busca-se dar uma nova forma à existência e à experiência humana, da qual defluem novos conceitos e novos valores. Visando o indivíduo, numa visão aristotélica, perquirir a busca de um ideal (do ótimo, que representa a plenitude da própria vida). Ou seja para quem a própria condição humana introduz o indivíduo numa busca incansável de sua realização e felicidade. 
Assim, a problemática desde estudo se tratamento dos conflitos familiares pode ser ampliada por meio da teoria dos sistemas? A resposta é sim se adotam-se hábitos e instituições mais flexíveis e abertos, que, recusando as estruturas rígidas e uniformes, hierarquizadas, do passado, fazem vigorar o ecletismo cultural, à informação, o estímulo das necessidades. Liberam-se os costumes, fazendo prevalecer a inclusão sobre a exclusão, abandonando-se as ideologias dominantes hegemônicas, ampliando-se nesse sentido a autonomia individual e a valorização pessoal do individuo. Essa abertura ideológica abarca os diversos planos da existência humana - as escolhas pessoais, a sexualidade, as barreiras ideológicas de expressão individual.

Atualmente, diante da diversidade cultural, principalmente em termos de família, a sociedade é convidada a vivenciar uma pluralidade de identidades e a conviver com novas formas de agrupamentos familiares.

A partir das teorias de Teubner e Luhmann, da forma especial como concebem a interação dos subsistemas sociais e seus códigos o que poderíamos chamar de fricções subsistêmicas, podemos chegar à concepção de que não é apenas a realidade social de atores que produz o direito, mas o inverso também procede: o direito cria realidade social, no sentido de que o código enseja que os atores sociais reordenem suas ações e expectativas conforme a lógica jurídica subjacente às interações (TEUBNER, 1989).

O reconhecimento de que vivemos na era global em sociedades multiculturais, compostas de uma pluralidade de identidades, instiga a reflexão a respeito das dificuldades de sustentar a importância da subjetividade para o Direito. Entendida aqui, como constituída por questões particulares que percorrem e transformam permanentemente a vida privada de cada indivíduo, como é o caso do amor, simbolicamente atribuídas pela co-evolução sistemica. A teoria sistêmica, portanto, permite a compreensão de processos coletivos, impiricamente constatáveis, em que o centro da ação não está localizado em forças macro ou microssociológicas, mas no código sistêmico do direito.

\section{REFERÊNCAS}

ARENDT, Hannah. A condição humana. 10. ed. Rio de Janeiro: Forense Universitária, 2004. 
ANDRIGHI, Fátima Nancy; KRÜGER, Cátia Denise Gress. Coexistência entre a socioafetividade e a identidade biológica - uma reflexão. In: BASTOS, Eliene Ferreira; AGUIAR, Odílio Alves. A propósito da problemática do mal em Hannah Arendt. Grifos, Chapecó, n. 13, nov. 2002.

AIRES, Philppe. História social da criança e da família. Rio de Janeiro: LTC, 1981.

BAKAS, Adjiedj. O futuro do amor - intimidade, sexo, união e solidão na nova ordem mundial.

Adjiedj. O futuro do amor - intimidade, sexo, união e solidão na nova ordem mundial. São Paulo: A Girafa, 2011.

BAUMAN, Zygmunt. O mal-estar da pós-modernidade. Rio de Janeiro: Jorge Zahar, 1998. Ensaios sobre o conceito de cultura. Tradução de Carlos A. Medeiros. Rio de Janeiro: Zahar, 2012.

Amor líquido. Rio de Janeiro: Jorge Zahar, 2004.

Modernidade líquida. Rio de Janeiro: Jorge Zahar, 2001.

A sociedade individualizada: vidas contadas e histórias vividas. Rio de Janeiro: Jorge Zahar, 2008.

Identidade. Tradução de Carlos Alberto Medeiros. Rio de Janeiro: Jorge Zahar Editor, 2005.

BECK, Ulrich; Elisabeth Beck G. El normal caos do amor. Barcelona: El Roure Editorial, 1998.

Ulrich. Liberdade ou Capitalismo. São Paulo: UNESP, 2002.

Ulrich. Risk Society. Towards a New Modernity. London: Sage Publications, 1992.

BOURDIEU, Pierre. A dominação masculina. 2. ed. Rio de Janeiro: Bertrand Brasil, 2002.

BOURDIEU, Pierre. A dominação masculina. Tradução de Maria Helena Kühner. 4 ed. Rio de Janeiro: Bertrand Brasil, 2005. 
BOURDIEU, Pierre. O poder simbólico. Tradução Fernando Tomaz. 2 ed. Rio de Janeiro: Bertrand Brasil, 1998.

BOURDIEU, Pierre. O senso prático. Tradução Maria Ferreira. Petrópolis: Vozes, 2009.

BEAUVOIR, Simone de. O segundo sexo: fatos e mitos. Tradução de Sérgio Milliet. 4. ed. São Paulo: Difusão Européia do Livro, 1970.

CASTRO, Carlos Roberto Siqueira. A difícil igualdade: os direitos da mulher como direitos humanos. In: TABAK, Dany; VERUCCI, Florisa (orgs.). Rio de Janeiro: Relume - Dumará, 1994.

CASTELLS, Manuel. La era de la información: Economía, sociedad y cultura. Volume II: El Poder de la Identidad. Madrid: Alianza Editorial, 1998.

O poder da identidade. Vol.2, São Paulo: Paz e Terra, 2000.

DELEUZE, Gilles, Félix Guattari. Mil Platôs: capitalismo e esquizofrenia. vol.1. Rio de Janeiro: Editora 34, 1996.

GIDDENS. Anthony. A terceira via. Tradução Maria Luiza X. de A. Borges. 5. ed. Rio de Janeiro, São Paulo: Editora: Record., 2005.

HONNETH, Axel. Luta por reconhecimento, a gramática moral dos conflitos sociais. São Paulo: Editora 34, 2003.

FOUCAULT, M. História da sexualidade - 1. A Vontade de saber. Lisboa: Edições António Ramos, 1977.

FOUCAULT, Michael. Histoire de la sexualité. La volonté de savoir. Paris Gallimard, v. I, 1976.

Microfísica do poder. Rio de Janeiro: Graal, 2003.

FERRAJOLI, Luigi. A soberania no mundo moderno. São Paulo: Martins Fontes, 2000.

FELIX, Luciane. Amor líquido. Sobre a fragilidade dos laços humanos. In: Jornal Carta Forense, abr. 2010, p. A 24. 
FURASTÉ, Pedro Augusto. Normas técnicas para o trabalho científico: elaboração e formatação. Porto Alegre: Brasul, 2006.

GOHN, G. As diferenças finas: de Simmel a Luhmann. In: Revista Brasileira de Ciências Sociais. vol. 3, n. 38. São Paulo, Outubro, 1998.

Abordagens teóricas no estudo dos movimentos sociais na América Latina. In:

Caderno CRH: Dossiê. Salvador, v. 21, n. 54, set./dez. 2008, p. 439-455.

LACAN, Jacques. Da psicose paranóica em suas relações com a personalidade. Rio de Janeiro: Forense Universitária, 1989.

FERRY, Luc. A revolução do amor por uma espiritualidade laica. Rio de Janeiro: Objetiva, 2012.

Luc. Família amo vocês, politica privada na era da globalização. Rio de Janeiro: Objetiva, 2008.

FURTADO, José Luiz. Amor. São Paulo : Globo, 2009.

LUHMANN, Niklas. O amor como paixão para a codificação da intimidade. Rio de Janeiro: Bertrand Brasil, 1991.

Risk: a sociological theory. New York: Aldine de Gruyter, 1993.

. Sociedad y sistema: la ambición de la teoria. Barcelona: Ediciones Pidós Ibérica, 1991.

Sociologia do Direito I. Rio de Janeiro: Tempo Brasileiro, 1983.

La sociedad de la sociedad. México: Herder, 2007.

MILL, John Stuart. A sujeição das mulheres. Coimbra: Almedina, 2006.

MORIN, Edgar. Sete saberes necessários à educação do futuro. São Paulo: Cortez; Brasilia, DF: Unesco, 2000.

OST, François. Raconter La Loi: Aux Sources de L'Imaginaire Juridique. Paris: Odile Jacob, 2004

OST, François. Contar a Lei - As fontes do imaginário jurídico. Tradução de Paulo Neves. São Leopoldo: Editoria Unisinos, Coleção Díke, 2005.

ROUDINESCO, Elisabeth. A família em desordem. Rio de Janeiro: Zahar, 2003.

Revista de Sociologia, Antropologia e Cultura Jurídica | e-ISSN: 2526-0251 | Maranhão | v. 3 | n. 2 | p. 85 - 106 | Jul/Dez. 2017. 
ROCHA, Leonel Severo, Schwartz, Germano, Clam, Jean. Introdução à Teoria do Sistema Autopoiético do Direito. Porto Alegre: Livraria do Advogado, 2013.

ROCHA, Leonel Severo. Epistemologia jurídica e democracia. 2. ed. São Leopoldo: Editora Unisinos, 2003.

ROCHA, Leonel Severo Da epistemologia jurídica normativista ao construtivismo sistêmico. In: LEONEL SEVERO, SCHWARTZ, GERMANO, CLAM, JEAN. Introdução à Teoria do Sistema Autopoiético do Direito. Porto Alegre: Livraria do Advogado. ROCHA, L.S.; KING, M.; SCHWARTZ, G. 2009. A verdade sobre a autopoiese no Direito. Porto Alegre, Livraria do Advogado, 2005.

SARLET, Ingo Wolfgang. A eficácia dos direitos fundamentais. 3. ed. rev. atual. e ampl. Porto Alegre: Livraria do Advogado, 2003.

SIMMEL, Georg. Filosofia do Amor. Tradução de Eduardo Brandão. São Paulo: Martins Fontes. 2006.

TOURAINTE, Alan. Iguais e Diferentes. Poderemos viver juntos?, Rio de Janeiro: Vozes, 1997.

TAYLOR, Charles. Multiculturalismo: examinando a política de reconhecimento. Lisboa: Instituto Piaget, 1994.

TEUBNER, Guinter. O Direito como sistema autopoiético. Lisboa: Calouste Gulbenkian, 1989. 